\title{
Study of Instructional Model for Information Technology Fundamental Courses under MOOC Environment
}

\author{
A Case Study on "Internet \& Webpage Design"
}

\author{
CHEN Mingjing \\ School of Information, \\ Zhejiang University of Finance \& Economics, \\ Hangzhou 310018, China \\ major_chen@163.com
}

\begin{abstract}
MOOC has several characteristics such as open, diversified, massive and supporting to personalize interactive learning. It pushes high education reform to a new stage. How to improve existing teaching with MOOC has become a hot topic in current research. Both the information technology fundamental courses and MOOC have several common grounds, such as instructional method and their environment. "MOOC-ClassroomOffline” interactive instructional model organically unifies both of them, should be an efficient method to improve teaching method and enhance the teaching effect. Illustration shows that this model can improve both students' learning effect and their participation, and it can also provide reference for other basic courses.
\end{abstract}

Keywords-MOOC; New Constructivism; MOOC-ClassroomOffline; Instructional Model

\section{INTRODUCTION}

The whole society has entered the information age, information technology has become an important support for enterprises and institutions, and it has also been the essential skills of college graduates. In order to meet the social needs, the information technology fundamental courses have been set up as public courses, such as computer foundation, web design, program design, and so on. These courses have several common characteristics as follows: (1) the audiences are freshmen; (2) these courses are all based on computers; (3) the contents of these courses are based on the operation, etc. At present, teaching method has carried on many reform and new explorations, for example, designing flexible teaching steps; application of case teaching and examination reforms [1] and so on. All of these have obtained a certain effect. But there are still many problems in existing teaching as below: (1) the difference between students make the unified teaching cannot meet the their needs in different levels; (2) some theory or operation process cannot immediately be understood and accepted by the students; (3) teachers cannot understand the situation about students' learning comprehensively.

On the other hand, in recent years, the MOOC (Massive Online Open Courses) have developed rapidly, which are based on the network and for the masses. MOOC issue quality education resources through the Internet, and providing a complete learning experience. They have a strong impact on the current higher education system, which is regarded as "higher education's most profound technological transformation in more than 500 years" [2]. The MOOC create an open and fair learning environment, allow students to learn courses from famous university all over the world, and it is also possible to obtain credit certification. For this reason, many scholars believe that the MOOC will bring tremendous challenges and threats to the traditional higher education. At the same time, other scholars think that MOOC provide a greater platform for education, teachers and students can communicate, colleagues can learn from each other, students benefit advantages more than before. So MOOC will give education more vitality. Especially for information technology fundamental courses, students use computers as a main tool, meanwhile the MOOC also needs computer, the combination of them will have a unique advantage [3]; in the MOOC platform, teachers can interact with students, monitor students' experiments and operations online, using software to carry out real-time teaching effect assessment, which would promote the reform and development of information technology fundamental courses.

\section{RELATED WORK}

\section{A. MOOC's teaching model}

MOOC established and developed by world's famous universities, such as Stanford University, Harvard University and so on, gradually formed three open platforms: Udacity, Coursera and edX [3], and here are three typical MOOC's teaching models:

\section{- Online education}

This model is mainly achieved through a powerful teaching platform. It was widely used and large-scale spread in higher education in many countries, including the United States [4]. Due to platform's openness and convenience, students around the world can watch the courses' videos in internet, participate in the discussion, submit assignments, complete the course examination, and finally get the course credits. Because of low cost, convenience and without any limits, this model is suitable for students who have a strong interest in learning, and hope to learn other school curriculum. 


\section{- "flipped classroom"}

In China, ordinary online education is difficult to spread. In recent years, many colleges began to spring up a new teaching model named "flipped classroom", which blend online education and offline teaching. For example, in Peking University, flipped classroom combines MOOC and their own teaching [5]. The teaching process is generally as follows: at first, the students should learn online; then understand and consolidate the knowledge through classroom teaching; at last, they need to complete the online exercise and examinations. MOOC platform analyze learning data and feedback learning results online. This model fit for students learning their own school curriculum. By the combination of online and offline, it should achieve more interaction between teachers and students.

\section{- Assistant teaching}

This model is mostly support the school curriculum teaching. On the online platform, students can get more selective teaching resources, strengthen the interaction between teachers and students, and enhance the teaching effect analysis. For example, BUAA built MOOC platform for the majority of the experimental classes [6], embedded or referenced MOOC platform to traditional teaching. It also remarkably improved the effect of classroom teaching. Because of low construction cost, management mode, difficulty of implementation and compatibility with existing teaching, this model is most acceptable to the universities.

\section{B. New Constructivism}

According to the new constructivism theory, the learning in Internet age faces two major challenges: one is information overload, another is knowledge fragmentation. In order to solve them, new constructivism emphasizes to teach students learning to choose, that means to break the traditional knowledge system, select learning content according to the individual needs and interests, and construct personalized cobweb type knowledge structure. New constructivism also recommends learning knowledge from part to whole and integrating fragments of information and knowledge, then realizing internalization of knowledge and knowledge innovation. [7]

Based on the new constructivist theory, in addition to professional knowledge, teaching should teach students more skills, such as autonomous learning ability, self-choice, selfthinking ability, and so on. The teaching process in new situation can be divided into three stages:

- Inspiration and guidance

In the Internet age, the most important task of teachers is not only teaching, but also guiding students into the temple of knowledge in acceptable way, then using various methods, such as knowledge guidance, heuristic teaching or recommending related resources and etc., to encourage students to get more in-depth knowledge from the network or other resources, which fit their own characteristics and needs. In this situation, students are willing to pay more time and energy. This stage should be done before the class usually, and students would reserve knowledge by learning and imitating.

\section{- Communication and inquiry}

Tacit knowledge is easy to be forgotten without timely using. It is difficult for students who just get started to find appropriate situation to use it. A simple way to make them permanent is communicating with others. Communication can be not only sharing and discussing in the classroom, but also communicating and collaborating in group cooperation. This stage usually needs face-to-face, can be in classroom or afterschool. Students could consolidate their knowledge by discussion, learn from each other, and improve ability of expression.

\section{- Integration and innovation}

Both individual learning and group discussion are bound to be fragmented. They cannot be built to a complete knowledge system by students' own ability. It needs teachers analyzing comprehensive cases or setting open tasks, helping students to integrate existing learning and carry out some research and innovative learning. This stage differs from man to man. It usually fit for after school and may require long time for accumulation and insight.

All of these stages are not completely separated, but be an overlapped and iterative process. Students learning new knowledge in stage 1, then they can communicate with others in stage 2. This can help them to master knowledge better, and they need to integrate this knowledge in stage 3. After that, they need new knowledge and start a new stage 1, and so on. The new constructivism is in such a circular spiral, as shown in figure 1 .

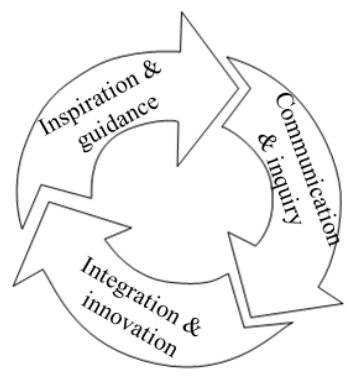

Fig.1 Three stages of new Constructivism

\section{OCO INTERACTIVE TEACHING MODEL}

Based on the existing MOOC teaching model and the new constructivism, the MCO (MOOC-Classroom-Offline) interactive teaching model is proposed, which combined MOOC platform, classroom (or computer room) and offline into a complete interactive experience for teaching, the overall structure is shown in figure 2.

The whole architecture is composed of three parts: the MOOC platform, the classroom and the offline.

\section{- MOOC platform}

MOOC platform is mainly used to publish the curriculum videos, unit tests, online Q\&A and learning statistics, etc. It could promote online interaction between teachers and students. Considering students' understanding rules, the videos last 


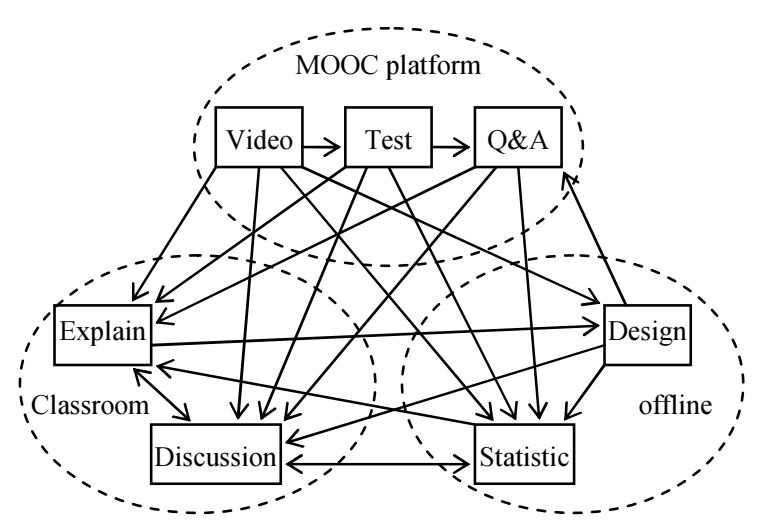

Fig. 2 Architecture of MCO model

about 5 minutes; few of them are longer than 8 minutes. Each of them focuses on a single knowledge point, containing explanations and manipulation, and all videos can constitute a complete knowledge system of the curriculum. At the end of each chapter, tests are set to help students reviewing knowledge. The contents of tests correspond to videos so that students could seek them easily. Q\&A is a simple BBS, and students could ask some questions or answer others students' questions and it would be awarded for their answering. Teachers could know about students' situation by counting their online activities such as learning time, test scores and interaction and adjust their class teaching contents. In addition, the platform could also issue some elective content to meet top students further study needs, on the other hand, prepare for keeping with the times.

\section{- Classroom}

Classroom is still the center of the whole teaching process. In classroom, students could understand the knowledge, discuss and apply them through the interaction between teachers and students or among students, and prepare for integration and innovation in curriculum design. Classroom teaching mainly includes analyzing and designing of advanced cases, explaining emphases and difficulties, panel discussion, etc. Through top-down decomposition, the practical comprehensive case change to the knowledge modules, then detailed to knowledge points, and finally be realized through the bottom-up approach. During the case analysis, some basic knowledge and their position in videos should be introduced to help students understanding them. Students could review them after class if they need. In addition, some emphases, difficulties and hot topics on the platform should be discussed occasionally.

\section{- Offline}

Because of the requirements of practical and innovative, online learning and classroom practice are far from enough. Students also need to complete the practice independently or with their team. Then they could consolidate the knowledge. Teachers should summarize feedbacks from online platform and classroom, control learning situation, and analyze teaching effects. Based on this information, they could appropriately adjust the content in classroom.

These three parts are independent outwardly, but they are closely related, as shown in Figure 2. For example, the content of classroom teaching needs to be differentiated from the videos, and timely reflect students' situations and provide supports to them, such as on-line tests, answering questions and completions of homework, etc. Teachers' statistics should be from the students' situations about video viewing, testing, online interactive and job completion, but also affect the classroom teaching content.

\section{TEACHING DESIGN}

\section{A. Teaching process}

Based on the new constructivism theory, the teacher's teaching process would be different from both traditional process and "flipped classroom" in the new environment. Firstly, the teachers' teams should make videos for the basic knowledge and collect relevant teaching resources, then issue on the platform; secondly, teachers should pre arranged learning tasks, in order to understand students' situation of online learning and testing, and adjust the contents and focus of classroom teaching; Thirdly, teachers need to answer students' questions, participate in students' online interaction, which could maintain students' enthusiasms. The process is shown in Fig. 3.

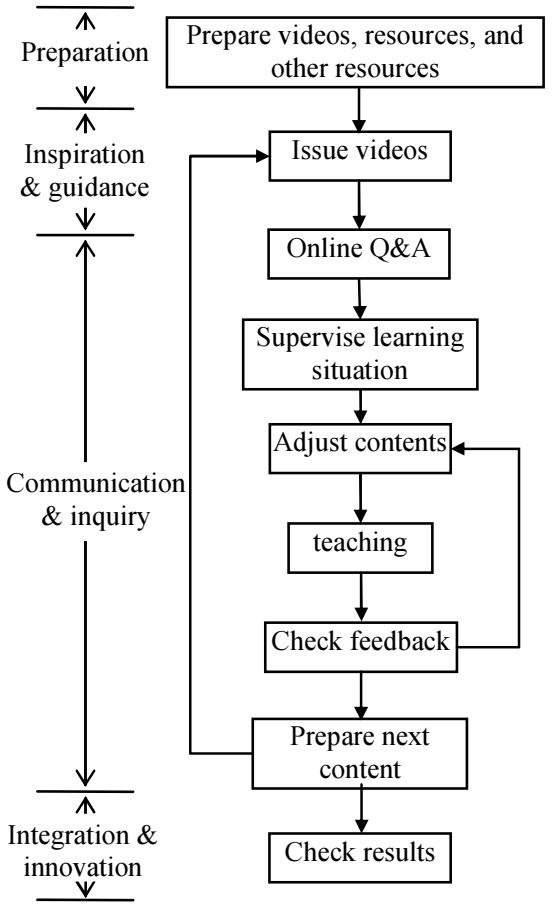

Fig. 3 Teaching process

At the same time, the learning process of the students has changed. Typical learning process could be divided into two categories: priori learning and posteriori learning. In priori learning, students should take full advantage of online resources to study before class. After mastering the basic knowledge, they would participate in classroom learning. Through case analysis and other forms, they would learn the knowledge to fully understand. The priori learning process is illustrated in Fig. 4. This process is suitable for students with weak foundation and poor understanding ability. In posteriori learning, students could participate in classroom learning 
without online preview. After cases study, they could understand the most parts of contents. Then they could make up for the parts which is remaining confused after school. The whole process is shown in Fig. 5. This process is suitable for students with strong learning ability and good foundation.

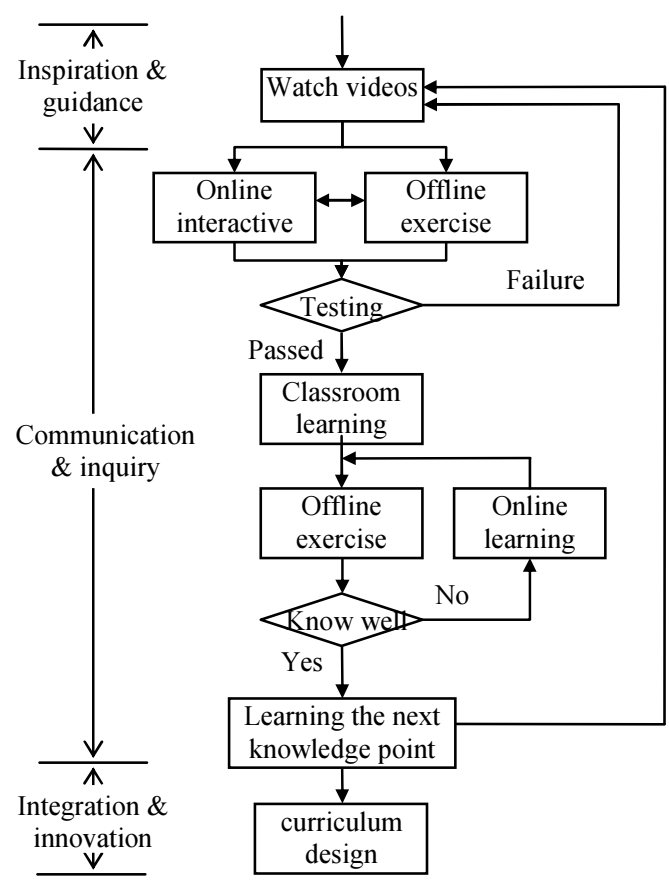

Fig. 4 Priori learning process

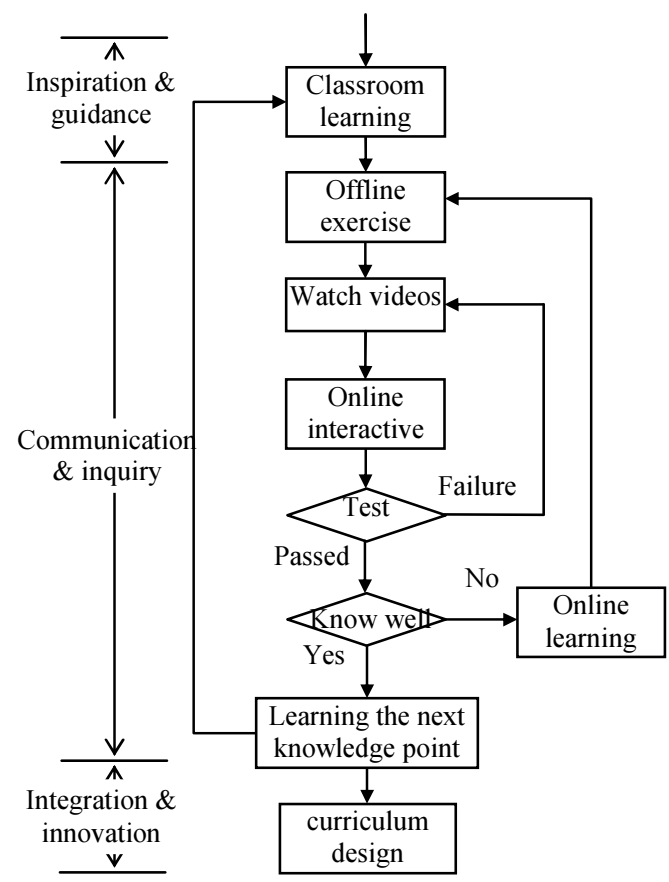

Fig. 5 Posteriori learning process

\section{B. Cases}

- Cases in video teaching

Video teaching in the whole teaching process covers basic knowledge as a guide. Most commonly the students haven't mastered the relevant knowledge when they watch videos. So, verifying case would be set in video teaching. Audiences could made simple works with the materials provided by teachers in order to grasp operations and related functions.

- Cases in classroom teaching

In classroom teaching, comprehensive works would be analyzed mainly, which are close to the practical application. They will be decomposed into several knowledge points by the guidance analysis, and be realized completely with students' interaction in classroom. Students would experience the whole designing process from simple to complex and from single to comprehensive.

\section{- Cases in curriculum designing}

Curriculum designing is the final examination of teaching. It could not only check students' situation of mastering knowledge, but also explore students' practical ability and innovation consciousness. It would be similar to Witkey mode: situations would be preset and general demand would be promoted, meanwhile it would still keep rooms for students so that they could develop their personal talents

\section{Examination}

MOOC itself is an open platform, students' learning way is very flexible, and advanced examinations need to be improved. The basic principle of the examination would be the combination of quantity and quality, process and result, team and individual. Class attendance and test paper examination are main evaluation methods in examination-oriented education and need to be diluted. Some process-based factors such as online learning time and the activity of the discussion area would be enhanced and result-based factors such as learning efficiency, the role of an individual in team and innovation of the final works. At the same time, mutual help and innovative learning could strengthen learning effect, so it would be recommended. Students are also encouraged to design the final works combining with the characteristics of the professional or their own expertise

\section{VALIDATION}

This chapter would use "Internet and web design" in Zhejiang University of Finance and Economics as an example. It has been set up on a local MOOC platform (www.wanke001.com). The whole course is divided into 7 chapters, a total of 75 teaching videos, which has covered the main knowledge points. In the second semester of the 20142015 school year, the teaching model has be piloted in 2 classes (total 157), the experimental period was 17 weeks and 3 hours per week. Removed the course introduction and summary, the actual teaching time are 15 weeks.

\section{A. Learning effect analysis}

The main examination is the final curriculum design, whose factors include HTML (15\%), CSS (25\%), JavaScript (15\%), material design (15\%), page layout $(20 \%)$, and originality $(10 \%)$, etc. Compared with similar classes in last semester, scores of each factor are shown in Figure 6 (centesimal system). 


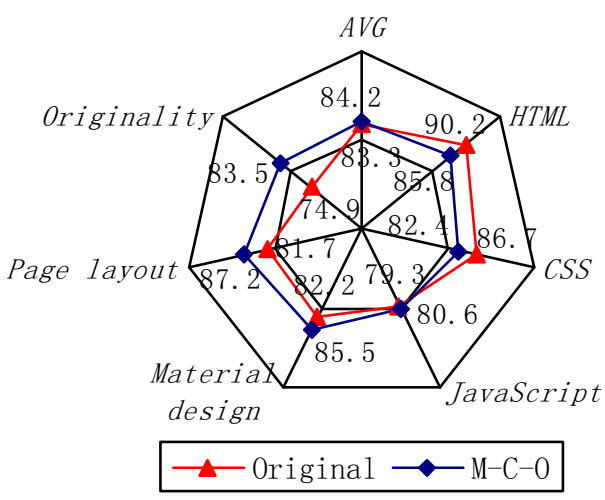

Fig. 6 Comparison of final score
This data indicates that it has a slight decline for students' scores in HTML, CSS and other basic knowledge, because the new teaching model uses case analysis and discussion to replace the hand grip type teaching, but they have a greater range of improvement in page layout, creativity, and other aspects which are becoming more and more important in practice. The distribution of scores shows that with the help of MOOC teaching, students' score distribution becomes more dispersed, and the number of high and low is increased compared with last term, which is shown in Fig. 7. It indicates that the new teaching model highlights "interest-based learning", in which students who has interest in learning has obvious advantages and those who are not interesting in web design cannot learn well.

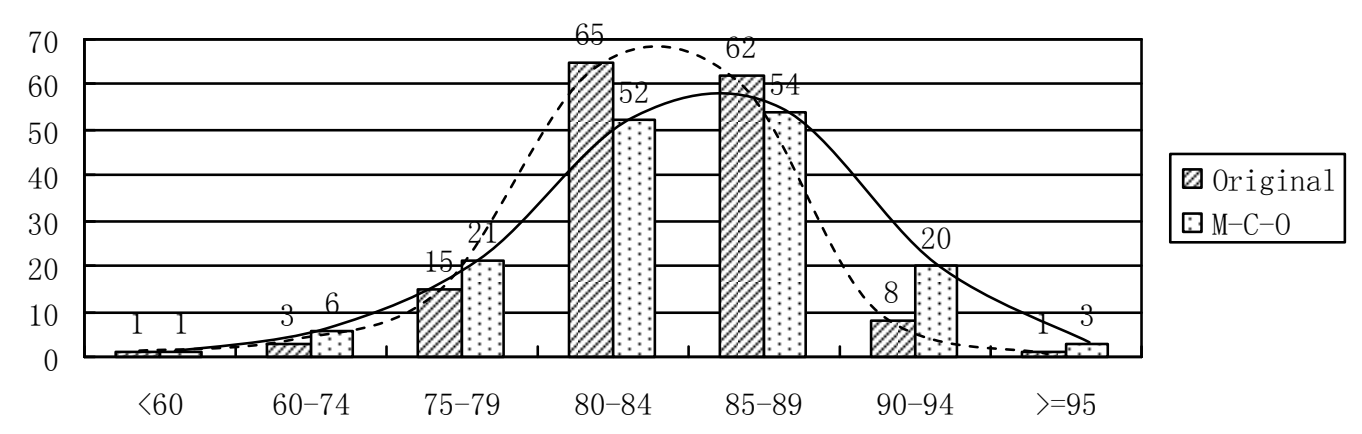

Fig. 7 Distribution of final score

\section{B. Participation degree analysis}

The author's school carries out "Students' Evaluation of Teaching" at the end of each semester; all students are required to evaluate both courses and teachers in several factors such as the teaching content, teaching methods, teaching effectiveness and classroom discipline, etc. The recent results show that students give the full affirmation to the new teaching model, and the score has improved obviously comparing with last semester.

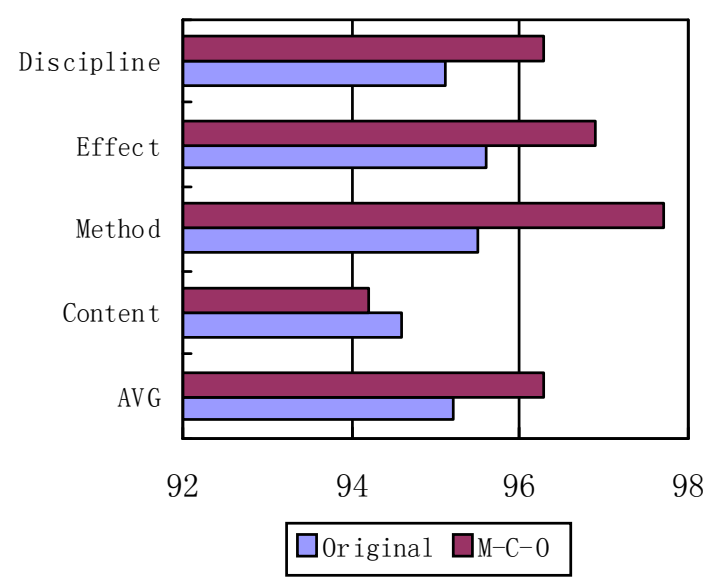

Fig. 8 Scores of "Students' Evaluation of Teaching"
"Students' Evaluation of Teaching" is a necessary project, and can not reflect the students' enthusiasm for taking part in classes truly. On the MOOC platform, students can also choose some interactive methods, such as online Q\&A, online notes, etc. According to statistics of platform, students' participation is shown in the following figure.

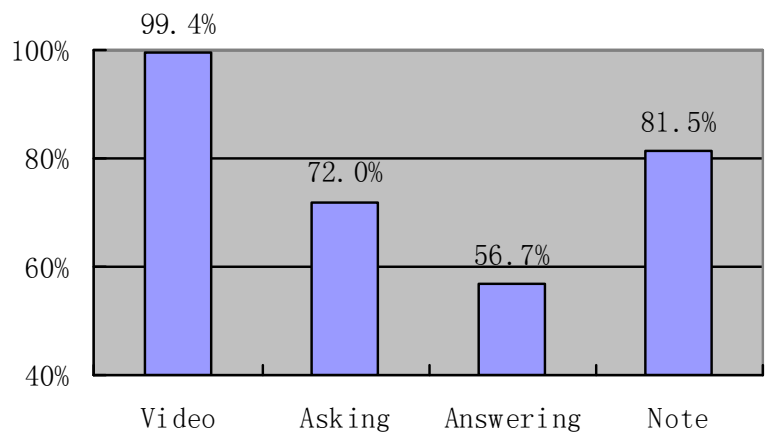

Fig. 9 Participation in online teaching

From the figure, the students' participation enthusiasm is high, interactive teaching model is effective; some students answered nearly 50 questions from others. By helping others, they consolidated their own knowledge and finally achieved excellent results. But "irrigation" still exists, and it is also needed to take measures to effectively improve the quantity and quality of students' participation. 


\section{CONCLUSION}

Information technology fundamental courses are basic and popularity courses. They require low theory and encourage students to study independently and innovatively. Both traditional "cramming" and the existing online teaching or the flipped classroom cannot be suitable for this kind of curriculum. $\mathrm{MCO}$ interactive teaching model is prompted to achieve more interactions between online teaching and classroom teaching. Students are encouraged to participate in teaching activities and accumulate knowledge fast and firmly. The data shows that the teaching model has obvious effect on improving students' average score and promoting students' autonomous learning. At the same time, the model also put forward a challenge to teachers. They not only need to allocate more energy to prepare teaching resources, pay attention to students' status, and answer the students' questions, but also need to adjust their roles, functions of guide and help replace functions of teaching and management. All of these are the important reasons which restrict its development.

\section{ACKNOWLEDGMENT}

We gratefully acknowledge the financial support from the Zhejiang Province Classroom Teaching Reform Project in Higher Education of China (No. kg2015253).

\section{REFERENCES}

[1] CHEN Ming-jing, JIN Xiao-tong. Investigation of "Internet and Webpage Design" Teaching Reform Based on Goal-oriented. Computer Education, 2014(6): 53-56.

[2] L. Rafael Reil. Inaugural Address(September 21,2012)[ OL]. $<$ http://president.mit.edu/speeches-writing/inaugural-address. $>$

[3] CHI Ya-qing, SONG Rui-qiang, LI Zhen-tao. Effection of the MOOC on Computer Course Teaching. Computer Engineering \& Science, 2014, 36(4): 164-168.

[4] WANG Wen-li. The Development of MOOC and its Influence on Higher Education[J]. Jiangsu Higher Education, 2013(2): 53-57.

[5] FENG Xue-song, WANG Qiong. Practice and Thinking of the First Batch of MOOCs in Peking University [J]. China University Teaching, 2013(12): 69-70

[6] SUN Qing; AI Ming-jing; CAO Qing-hua. Study on Opening and Sharing Experimental Teaching under MOOC Environment. Experimental Technology and Management, 2014(8):

[7] WANG Zhu-li. Preliminary Exploration of the New Constructivism Teaching Method[J]. Modern Educational Technology, 2014, 24(5): 511.

[8] ZENG Ming-xing et. Research on Flipped Classroom Model for Software Development Courses[J]. Research and Exploration in Laboratory, 2014, 33(2): 203-209.

[9] WANG Xiao-dong ZHANG Chen-jing-zi. The Application Research of Flipped Classroom in University Teaching[J]. Modern Educational Technology, 2013, 23(8): 11-16 